EDITORIAL

\title{
“PRIMEIRO TIVEMOS QUE MORRER": SAÚDE MENTAL EM TEMPOS DE COVID-19
}

A morte é um fenômeno inevitável, mas continua sendo capaz de desencadear emoções de várias matizes: sofrimento, saudade, raiva, tristeza, perda. E quando a morte se configura em milhares e estas acontecem de forma inesperada, a exemplo do vivenciado com a crise sanitária mundial provocada pela Covid-19? A morte é um assunto que as pessoas sempre tentam evitar, principalmente pela dificuldade de discutir as suas significações, que estão relacionadas com a finitude do ser. Mas com a chegada da pandemia do novo coronavírus, teve-se que conviver com a morte e o morrer e, consequentemente, encontrar formas de superação e adaptação em face de tantas perdas.

Em janeiro de 2020, a Organização Mundial da Saúde (OMS) declarou que o surto da doença causada pela Covid-19 poderia ser considerado uma Emergência de Saúde Pública de relevância internacional, com um grande nível de alerta $^{1}$. Desde então, o número de vidas perdidas avança exponencialmente; no mundo, ao final de novembro de 2020, já eram 1.338.100 mortes associadas à Covid-19. 0 Brasil ocupa o segundo lugar, com 169.016 mortes, no momento de escrita deste texto, superado apenas pelos Estados Unidos, com $255.678^{2}$.

Posto isto, reconhece-se, com preocupação, o impacto emocional provocado pela pandemia do novo coronavírus, o que exige maior atenção do poder público. É imprescindível um olhar mais acurado para as práticas de saúde mental durante e pós-pandemia, pois são incalculáveis os transtornos provocados nas pessoas que se infectaram, nos que perderam entes queridos e amigos, nos que não se adaptaram às mudanças de rotina, nos que possuem medo de se infectar e, principalmente, nos profissionais de saúde que estão direta e/ou indiretamente na linha de frente no combate à Covid-19. Vivencia-se um momento atípico e singular.

Estudos já evidenciam o impacto na saúde mental da população brasileira. Com o avanço da Covid-19 em todo o mundo, o número de mortos e infectados, as incertezas sobre como controlar a doença e o grau de sua gravidade, além da imprevisibilidade acerca do tempo de sua duração, associada à incerteza de tratamento e cura, caracterizam-se como fatores de risco e agravantes à saúde mental da população mundial³.

Pesquisas já sugerem que pessoas com suspeita de infecção pelo novo coronavírus podem desenvolver sintomas obsessivo-compulsivos, como a verificação repetida da temperatura corporal. Ademais, medidas de isolamento dos casos suspeitos, fechamento de universidades e escolas, distanciamento social de idosos e de outros grupos de risco, bem como as medidas restritivas de afastamento social, renda familiar diminuída e acesso a informações negativas sobre a doença, são estressores que podem contribuir com o surgimento de sofrimento psíquico ${ }^{4-6}$.

Vivencia-se uma situação de múltiplos casos de infecção e óbito em uma mesma família, gerando lutos constantes, introduzindo desafios adicionais às formas de se adaptar e lidar com as mortes. Mesmo não havendo perdas concretas diretamente ligadas a algum familiar ou amigos, cada pessoa pode experimentar sofrimento, por empatia, em relação aos indivíduos mais diretamente afetados, ou por estarem mais sensíveis a essa crise sanitária ${ }^{7}$.

As milhares de perdas provocaram e ainda estão provocando um sentimento de profunda tristeza, um luto coletivo. 0 luto pode ser experienciado de forma diferenciada, provocando crises e sobrecargas particulares em cada pessoa, com complicações no âmbito da saúde mental ${ }^{8}$. Alinhado a isso, reconhece-se que todos os fenômenos trazidos pela Covid-19 possibilitam de forma efetiva o surgimento de sofrimento psíquico, sugerindo um olhar mais atento para 0 aparecimento de alguns quadros de transtornos mentais durante e pós-pandemia 9 .

Só saberemos de fato a dimensão das consequências após passado o período de pandemia. Assim, esforços imediatos devem ser empregados em todos os níveis e pelas mais diversas áreas de conhecimento, a fim de minimizar 
resultados ainda mais negativos na saúde mental da população. Cabe, enfim, investir em adequada assistência à saúde e, sobretudo, na ciência em geral, para que esse período seja abreviado e que todos atravessem essa crise com menos danos possíveis ${ }^{10}$.

Enquanto isso, vamos cuidando uns dos outros e estimulando a transformação da ciência com vistas ao enfrentamento mais adequado das questões que afetam tão significativamente a sociedade contemporânea. Em tempo, convida-se à leitura dessa edição da SANARE - Revista de Políticas Públicas, na qual são divulgados importantes resultados de pesquisa que implicam no repensar das práticas cotidianas que envolvem a saúde das pessoas.

Boa leitura!

\section{Prof ${ }^{a}$ Dra. Eliany Nazaré Oliveira}

Docente do Curso de Enfermagem

Universidade Estadual Vale do Acaraú (UVA)

\section{REFERÊNCIAS}

1. Organização Pan-americana de Saúde. Folha informativa - COVID-19 (doença causada pelo novo coronavírus) [home-page on the internet]. 2020 [cited 2020 Nov 22]. Available from: https://www.paho.org/bra/index. php?option $=$ com content $\&$ view $=$ article $\& i d=6101$ : covid19\&Itemid $=875$

2. Brasil. Covid-19 no Brasil [home-page on the Internet]. Brasília: Ministério da Saúde; 2020 [cited 2020 Nov 22]. Available from: http://susanalitico.saude.gov.br/\#/dashboard/

3. Schmidt B, Crepaldi MA, Bolze SDA, Neiva-Silva L, Demenech LM. Impactos na Saúde Mental e Intervenções Psicológicas Diante da Pandemia do Novo Coronavírus (COVID-19). SciELO Preprints [serial on the internet]. 2020 [cited 2020 Nov 22];1(1):1-26. Available from: https://doi.org/10.1590/SCIELOPREPRINTS.58

4. Brooks SK, Webster RK, Smith LE, Woodland L, Wessely S, Greenberg N, et al. The psychological impact of quarantine and how to reduce it: rapid review of the evidence. Lancet [serial on the internet]. 2020 [cited 2020 Nov 23];95(10227):912-20. Available from: https://www.thelancet.com/pdfs/journals/lancet/PIIS0140$6736(20) 30460-8 . p d f$

5. Duarte MQ, Santo MAS, Lima CP, Giordani JP, Trentini CM. COVID-19 e os impactos na saúde mental: uma amostra do Rio Grande do Sul, Brasil. Cien Saude Colet [serial on the internet]. 2020 [cited 2020 Nov 23];25(9):3401-11. Available from: http://www.scielo.br/scielo.php? script $=$ sci arttext\&pid $=$ S1413-81232020000903401\&lng $=$ en

6. Zandifar A, Badrfam R. Iranian mental health during the COVID-19 epidemic. Asian J Psychiatr [serial on the internet]. 2020 [cited 2020 Nov 23];51(101990):1. Available from: https://www.sciencedirect.com/science/ article/pii/S1876201820300988?via\%3Dihub

7. Crepaldi MA, Schmidt B, Noal DS, Bolze SDA, Gabarra LM. Terminalidade, morte e luto na pandemia de COVID-19: demandas psicológicas emergentes e implicações práticas. Estud psicol (Campinas) [serial on the internet]. 2020 [cited 2020 Nov 23];37:e200090. Available from: http://www.scielo.br/scielo.php?script=sci arttext\&pid $=$ S0103166X2020000100508\&lng =en \&nrm $=$ iso

8. Santos EM, Sales CA. Familiares enlutados: compreensão fenomenológica existencial de suas vivências. Texto Contexto Enferm [serial on the internet]. 2011 [cited 2020 Nov 23];20(n. spe):214-22. Available from: https://www.scielo.br/scielo.php?pid=S0104-07072011000500027\&sC $\underline{\text { ript }=s c i}$ abstract\&tlng $=p t$

9. Oliveira EN. Mental Health during the new Coronavirus Pandemic: some necessary reflections. Research, Society and Development [serial on the internet]. 2020 [cited 2020 Nov 24]; 9(8):e413985478. Available from: https://rsdjournal.org/index.php/rsd/article/view/5478

10. Faro A, Bahiano MA, Nakano TC, Reis C, Silva BFP, Vitti LS. COVID-19 e saúde mental: a emergência do cuidado. Estud psicol (Campinas) [serial on the internet]. 2020 [cited 2020 Nov 24];37:e200074. Available from: https://www.scielo.br/scielo.php?script=sci arttext\&pid=S0103-166X2020000100507 